\title{
Radiance in Reclamation
}

\author{
Ali Javeed
}

\begin{abstract}
In the sharp frosty winds of the morning of January 9th, 2019, Indigenous activist group Idle no More and their allies shut down the Bloor Viaduct, a well-used truss arch bridge in Tkaronto, Ontario, Kanata (Three Fire Territories) that connects the city's east-side to its downtown core. The action took place during rush hour in solidarity with the Wet'suwet'en First Nation. The Canadian government was once again violating unceded land by mobilizing armed federal law enforcement to forcibly remove the nation from their land in order to build a gas pipeline. In response to this violence, allies throughout the city, myself among them, decided to show Tkaronto that it was not business as usual by bringing traffic on the Viaduct to a halt. Importantly, the bridge looms over the Don River. Reclamation of this space was therefore a reminder of the sanctity of water, gesturing to the fact that it is a privilege to be able to access clean water, while also reminding us of the threat of contamination posed by the pipelines' development. As the day came to an end and the sun retreated, cycling through its farewell hues of yellow and orange, the elders began to sing. We round danced, our bodies flowing as one like the river beneath us. Our melodic voices of hope and mourning, joining the gusts of wind that whistled between the bridge supports. After the protest, we continued to chant as we walked back, fists raised with the awareness that, although this action was over, our spirits had been rekindled for the next one. This photo essay seeks to echo the calls of resistance of that day. I capture the warm hopeful tones of the sunset in an otherwise frigid colour scheme, while using wide angles to capture the scope of attendance, and a low depth of field to center the role of femme-identifying water protectors in the movement..
\end{abstract}

\section{Keywords}

photography, resistance Tkaronto, Round Dance, Wet'suwet'en First Nation 

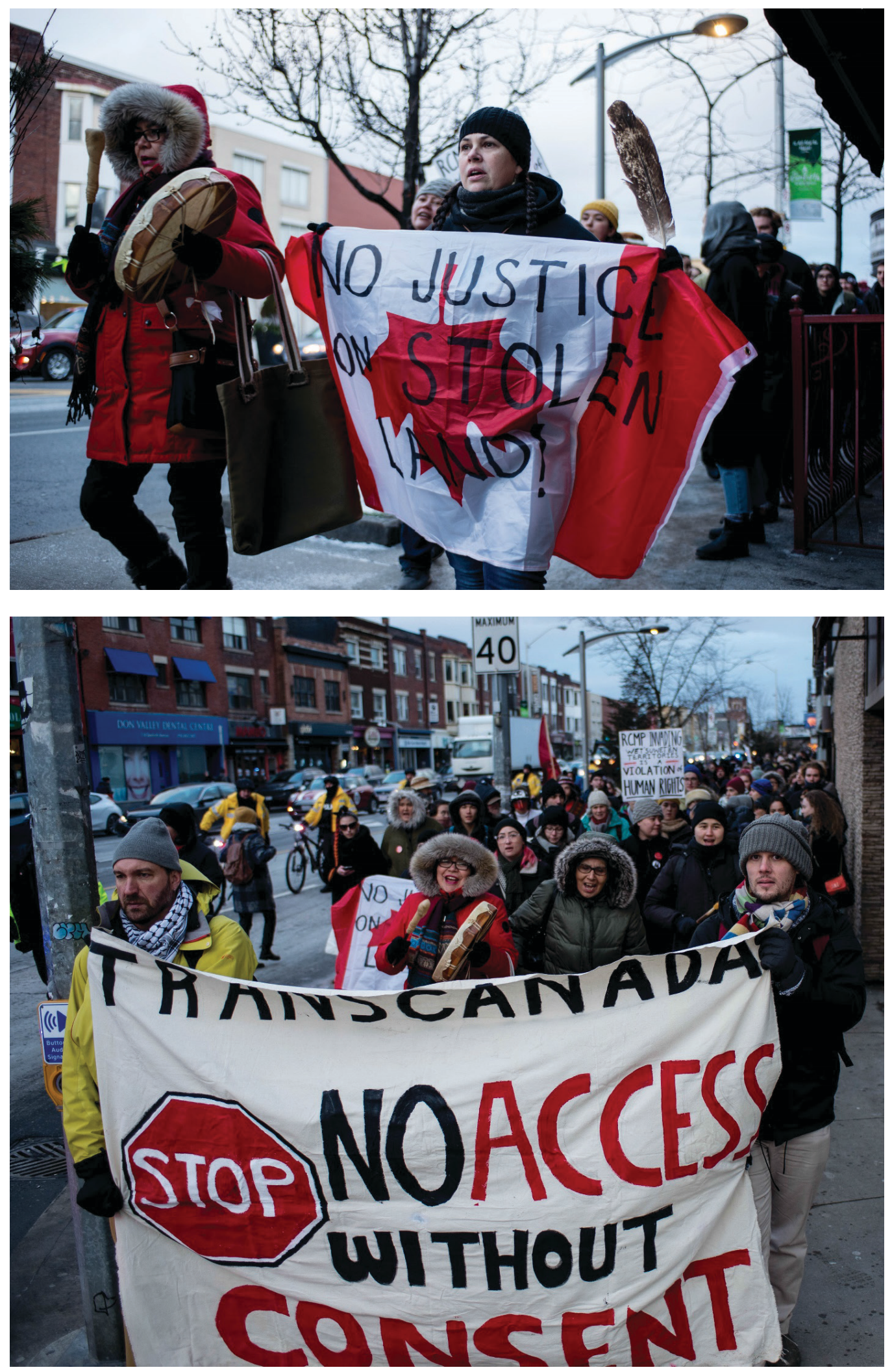

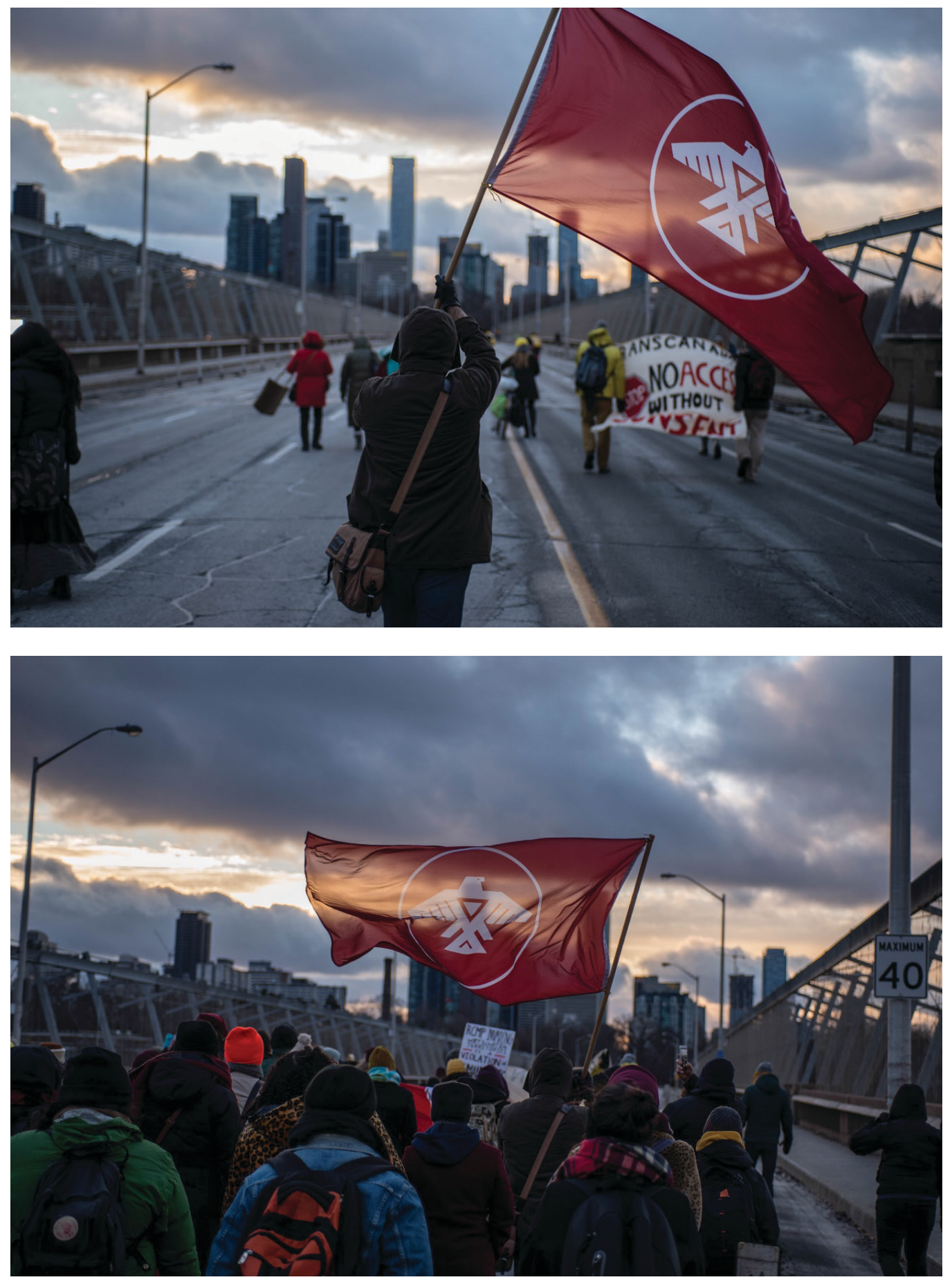

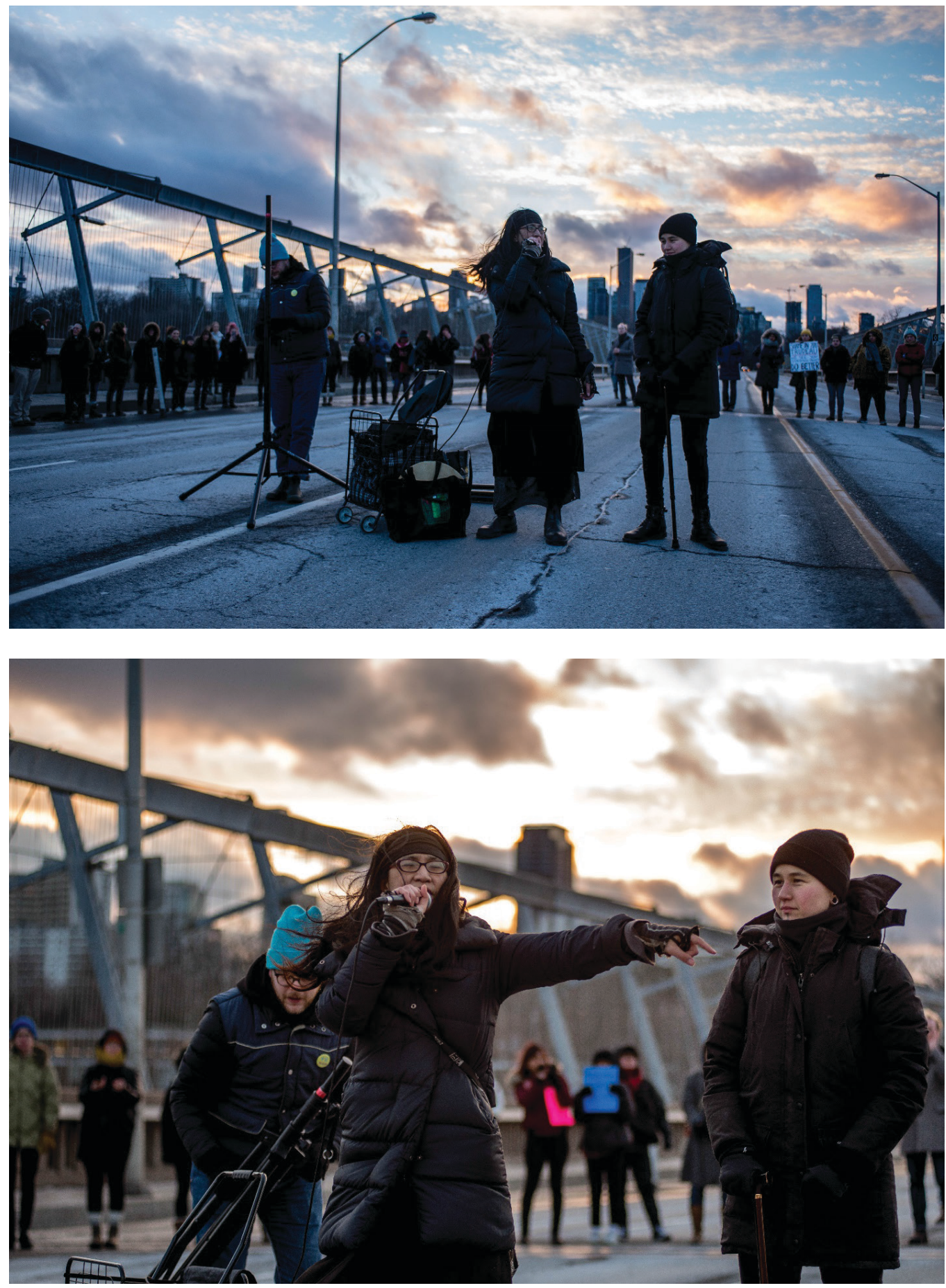

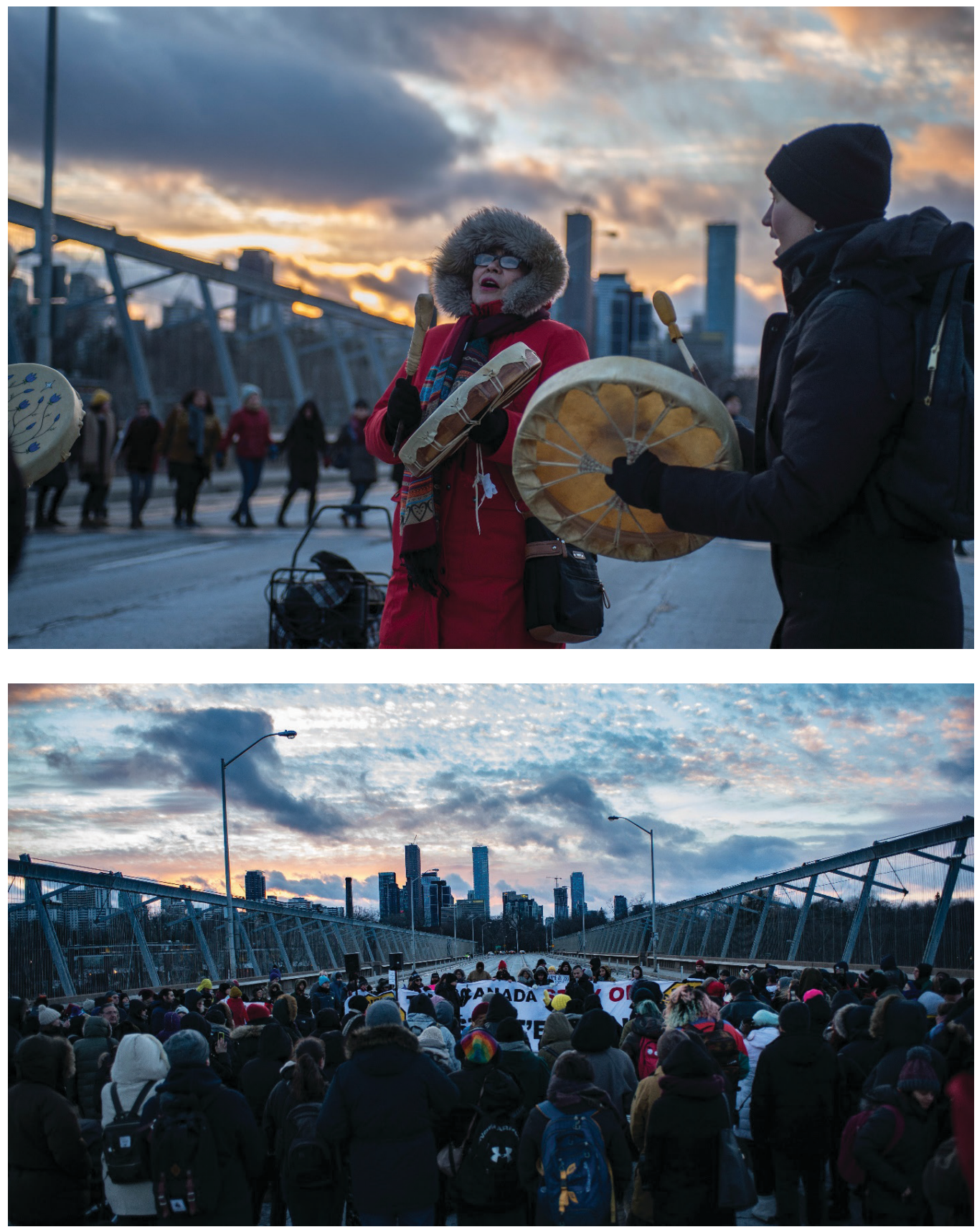

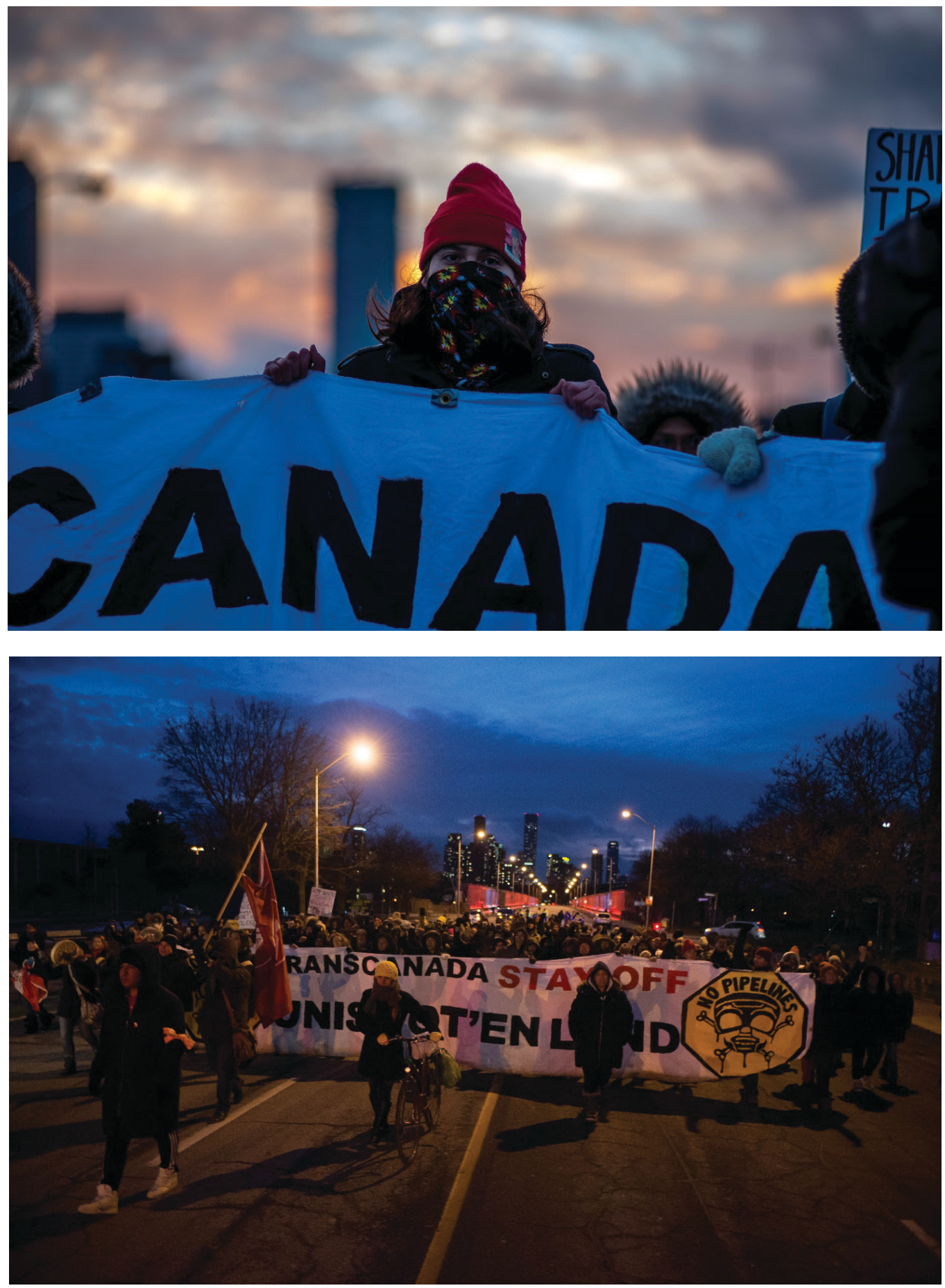

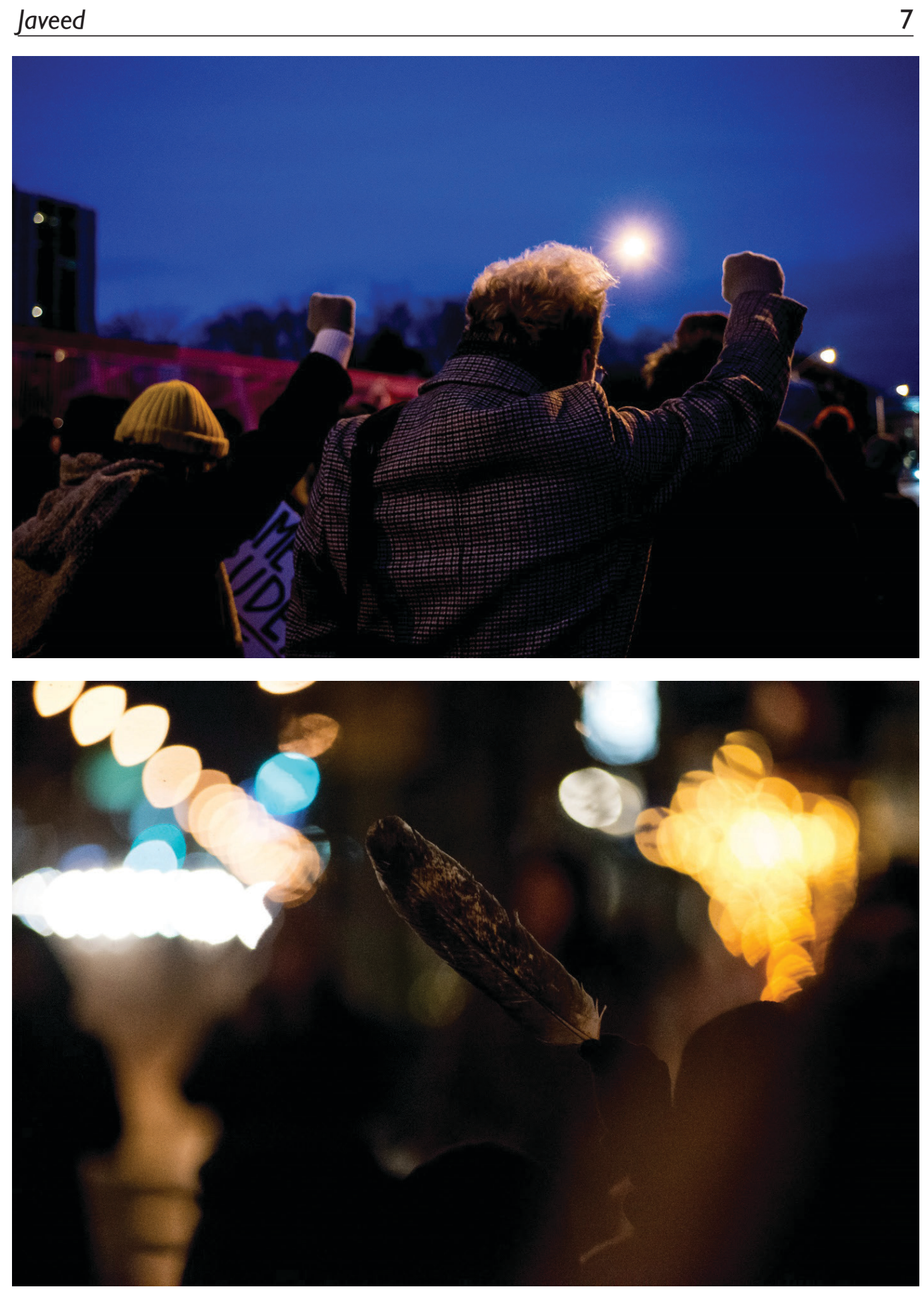


\section{Author Biography}

Ali Javeed is an undergraduate student pursuing an Honours Bachelor of Science in Psychology at the University of Toronto. His research interests are broadly located in the topic of social perception: the process with which we gather information from our environments to make social judgements of things like intention, causality or expectations of people and things around us. Through social perception we may implicitly create or accept a set of behaviours that are "normal" for a given environment like a public space. Public social norms (e.g. where to stand on an escalator) may seem trivial, but Ali argues in his present research that based on your political ideology, these simple social norms may actually hold a moral weight. Another one of his research topics is in emotion, where he is collecting longitudinal data of how people are using information-seeking as a way to regulate their emotions during the COVID-19 pandemic. While his brain belongs to science, his heart is reflected in photography as he independently documents actions around Toronto. Ali is also born and raised in Scarborough and may say "styll" unprovoked. More of his photos, and information about his research can be found at www.alijaveed.com. 